\title{
Penerapan Perencanaan Agregat untuk Meminimumkan Biaya Produksi (Studi pada CV. X)
}

\author{
Astri Refa Febryanti ${ }^{1}$, Asni Mustika Rani ${ }^{2}$ \\ ${ }^{1,2}$ Fakultas Ekonomi dan Bisnis-Manajemen, Universitas Islam Bandung (UNISBA) \\ ${ }^{1}$ astrirefa@gmail.com, ${ }^{2}$ asnimustika@unisba.ac.id
}

\begin{abstract}
ABSTRAK
Perencanaan produksi digunakan sebagai langkah awal ketika perusahaan akan melakukan proses produksi. CV. X adalah perusahaan konveksi yang memproduksi pakaian. Tujuan dari penelitian ini yaitu dapat merencanakan proses produksi dan menghitung alternatif strategi perencanaan agregat yang dapat meminimumkan biaya produksi untuk memaksimalkan keuntungan. Strategi perencanaan agregat ini menggunakan tiga metode yaitu level strategy, chase strategy, dan mixed strategy. Metode chase strategy menghasilkan biaya yang lebih rendah dibandingkan dengan metode lain dengan total biaya Rp. 4.985.861.595. Berdasarkan kondisi perusahaan, chase strategy sebaiknya digunakan oleh perusahaan untuk mengurangi biaya produksi.
\end{abstract}

Kata Kunci: perencanaan produksi, level strategy, chase strategy, mixed strategy

\section{ABSTRACT}

Production planning used as the first step when the company going to start the production process. CV. $X$ is a company in convection that produces clothing. The purpose of this study is to be able to plan the production process and calculate alternative aggregate planning strategies that can minimize production costs to maximize profits. This aggregate planning strategy uses three methods. The methods are level strategy, chase strategy, and mixed strategy. The chase strategy method has a lower cost compared to other methods with a total cost of Rp. 4.985.861.595. Based on company conditions, a chase strategy should be used by companies to reduce production costs.

Keywords: production planning, level strategy, chase strategy, mixed strategy

\section{PENDAHULUAN}

\section{Latar Belakang}

Perkembangan dunia bisnis pada saat ini semakin berkembang pesat sehingga persaingan yang terjadi semakin ketat (Febriyanti, Koesdiningsih dan Rani, 2019). Produk fashion termasuk produk yang memiliki tingkat persaingan sangat ketat (Niagahoster, 2020). Pelaku usaha fashion dituntut untuk semakin memperbaiki kualitas dan ketepatan waktu produksi untuk menjadi unggul dibandingkan pesaingnya. Perusahaan harus dapat mempertahankan konsistensinya untuk bertahan dalam industri fashion yang dinamis ini (Rani, 2019).

CV. X adalah perusahaan konveksi yang mampu menghasilkan produk fashion seperti kaos, jaket, kemeja, sweater, hoodie, dll. Perusahaan ini memproduksi berdasarkan pesanan konsumen. Agar konsumen mendapatkan pelayanan yang terbaik, perusahaan dituntut untuk memenuhi pesanan dengan tepat waktu. Berikut ini adalah data permintaan dan produksi untuk produk kaos di CV. X pada periode April 2019-Maret 2020: 
Tabel 1. Permintaan Kaos Periode April 2018 - Maret 2019

\begin{tabular}{|c|c|c|c|c|c|c|c|c|c|c|c|c|c|}
\hline Bulan & Apr & Mei & Jun & Jul & Agust & Sept & Okt & Nov & Des & Jan & Feb & Mar & Total \\
\hline Permintaan & 4.256 & 6.955 & 5.532 & 6.747 & 5.721 & 5.647 & 5.422 & 4.166 & 5.615 & 7.900 & 8.520 & 5.620 & $\mathbf{7 2 . 1 0 1}$ \\
\hline
\end{tabular}

Sumber: CV. X (2019)

Berdasarkan Tabel 1 terlihat bahwa permintaan kaos setiap bulannya berfluktuasi. Untuk memenuhi tuntutan permintaan konsumen, perusahaan harus menerapkan strategi terbaiknya agar dapat memenuhi permintaan yang akan datang. Perencanaan produksi yang kurang baik akan menyebabkan biaya produksi menjadi mahal.

Kegiatan produksi yang buruk harus dihindari oleh perusahaan yang memiliki permintaan berubah-ubah melalui perencanaan produksi yang tepat. Untuk memudahkan perusahaan melakukan perencanaan proses produksi, maka dapat dilakukan perencanaan agregat. Perencanaan agregat dilakukan melalui optimalisasi sumber daya dengan menentukan keputusan terbaik untuk merekrut atau memberhentikan karyawan, harus atau tidaknya karyawan melakukan lembur, paruh waktu, atau melakukan subkontrak terhadap perusahaan lain untuk memenuhi permintaan yang telah diterima oleh perusahaan (Heizer, Render dan Munson, 2017).

\section{Identifikasi Masalah}

Perencanaan agregat dapat memberikan kemampuan merespon permintaan yang berfluktuasi, maka hal ini menjadi penting dilakukan dalam menentukan waktu produksi pada jangka menengah dan menentukan jalan terbaik untuk memenuhi permintaan dengan tetap mempertimbangkan efisiensi biaya. Perencanaan agregat menjadi tanggung jawab penting bagi seorang manajer operasi dan kunci dari penggunaan sumber daya yang ada secara efisien sehingga proses produksi dapat berjalan dengan baik dan terkendali. Dengan adanya perencanaan agregat diharapkan mampu membuat perusahaan memenuhi permintaan yang berfluktuasi dengan menyesuaikan nilai produksi, tingkat persediaan, tingkat tenaga kerja, tingkat subkontrak, tingkat lembur, dan variabel lainnya yang dapat dikendalikan sehingga dapat meminimumkan biaya produksi pada perusahaan.

Berdasarkan identifikasi masalah tersebut, penelitian ini mencoba untuk menganalisis bagaimana penerapan perencanaan agregat produk kaos pada $\mathrm{CV}$. X saat ini dan memberikan rekomendasi strategi perencanaan agregat menggunakan metode level strategy, chase strategy, dan mixed strategy.

\section{Rumusan Masalah}

Rumusan masalah yang diambil berdasarkan latar belakang yang telah diuraikan di atas yaitu bagaimana perencanaan agregat dengan metode level strategy, chase strategy, dan mixed strategy dapat meminimumkan biaya produksi pada CV. X. 


\section{LANDASAN TEORI}

\section{Perencanaan Agregat}

Perencanaan agregat dapat meningkatkan alternatif dalam pemanfaatan kapasitas yang bisa dipertimbangkan dalam manajemen. Perencanaan dan pengendalian operasi pada tingkat yang lebih luas harus dilakukan melalui perencanaan agregat tanpa mengabaikan rincian produk-produk secara individu, penjadwalan rinci fasilitas, dan sumber daya manusia. Perencanaan agregat merupakan perencanaan kegiatan operasional jangka menengah yang memberikan tingkat output agar sesuai dengan tingkat permintaan di masa yang akan datang.

Menurut (Schroeder \& Goldstein, 2018), perencanaan agregat adalah aktivitas mencocokkan penawaran output dengan permintaan dalam rentang waktu menengah. Kerangka waktu antara enam bulan dan dua tahun kedepan, atau rata-rata sekitar satu tahun. Serta menurut (Akhmad, 2018), perencanaan agregat berkaitan dengan pengimbangan antara supply dan output selama kurang lebih 12 bulan ke depan. Periode peramalan dilakukan 12 bulan ke depan dikarenakan masuk dalam kategori perencanaan jangka menengah.

\section{Metode Perencanaan Agregat}

(Reid \& Sanders, 2013) membagi perencanaan agregat ke dalam tiga metode yaitu: (1) aggregate plan yaitu mempertahankan tenaga kerja stabil dan menghasilkan jumlah produk yang sama di masing-masing periode; (2) chase aggregate plan yaitu strategi yang menghasilkan output sesuai dengan apa yang dibutuhkan untuk memenuhi permintaan setiap periode; dan (3) hybrid aggregate plan yaitu strategi perusahaan mempertahankan tenaga kerja yang stabil ditambah dengan mengatur persediaan dan melakukan lembur untuk memenuhi permintaan.

Sedangkan menurut (Krajewski, Malhotra \& Ritzman, 2016), metode perencanaan agregat terdiri atas: (1) level strategy yaitu perusahaan mengatur tenaga kerja tetap konstan (kecuali pada awal horizon perencanaan); (2) chase strategy yaitu memvariasikan kapasitas waktu reguler dengan permintaan, tidak memerlukan inventory, overtime atau undertime; (3) mixed strategy yaitu memvariasikan seluruh pilhan strategi termasuk pengaturan persediaan, pekerja paruh waktu, subkontrak, backorders, dan stockouts.

\section{METODE PENELITIAN}

Penelitian ini merupakan penelitian deskriptif kuantitatif dengan menggunakan metode studi kasus. Data yang telah diperoleh akan dideskripsikan, dianalisis, dan diteliti untuk mengetahui permasalahan pada objek yang diteliti dengan menggunakan strategi perencanaan agregat menggunakan metode level strategy, chase strategy, dan mixed strategy untuk dibandingkan dan dipilih biaya produksi yang paling minimum.

\section{Perhitungan Perencanaan Agregat}

Perhitungan perencanaan agregat dilakukan dengan langkah: (1) mengumpulkan data produksi di perusahaan melalui wawancara dan observasi; (2) meramalkan permintaan produk untuk masa yang akan datang menggunakan rumus least square 
Dimana:

$$
y=a+b x
$$

$y=$ Variabel yang dicari

$a=$ Nilai trend pada tahun dasar

$b=$ Rata-rata pertumbuhan nilai trend tiap tahun

$x=$ Variabel waktu

Untuk mencari konstanta (a) dan parameter (b) rumusnya adalah:

$$
\begin{gathered}
a=\frac{\sum y}{n}-b \frac{\sum x}{n} \\
b=\frac{n \sum x y-\sum x \sum y}{n \sum x^{2}-(x)^{2}}
\end{gathered}
$$

(3) menghitung perencanaan agregat dengan metode-metode level strategy (total biaya = upah tenaga kerja + biaya persediaan + biaya produksi), chase strategy (total biay a $=$ upah tenaga kerja + biaya rekrut/pecat + biaya produksi), dan mixed strategy (total biaya $=$ upah tenaga kerja + biaya persediaan + biaya lembur + biaya subkontrak + biaya produksi); dan (4) membandingkan metode yang menghasilkan biaya produksi terkecil.

\section{PEMBAHASAN}

\section{Peramalan Permintaan Kaos}

Berikut ini adalah peramalan kaos dengan menggunakan metode least square:

Tabel 2. Perhitungan Peramalan Permintaan Kaos

\begin{tabular}{|l|r|r|r|}
\hline \multicolumn{1}{|c|}{ Measure } & \multicolumn{1}{c|}{ Value } & Future Period & \multicolumn{1}{c|}{ Forecast } \\
\hline Error Measures & & 13 & 6806,485 \\
\hline Bias (Mean Error) & 0 & 14 & 6929,265 \\
\hline MAD (Mean Absolute Deviation) & 994,259 & 15 & 7052,045 \\
\hline MSE (Mean Squared Error) & 1393930 & 16 & 7174,824 \\
\hline Standard Error (denom=n-2=10) & 1293,335 & 17 & 7297,604 \\
\hline $\begin{array}{l}\text { MAPE (Mean Absolute Percent } \\
\text { Error) }\end{array}$ & $16,98 \%$ & 18 & 7420,384 \\
\hline Regression line & & 19 & 7543,164 \\
\hline Demand(y)=5210,348 & & 20 & 7665,943 \\
\hline$+122,78^{*}$ Time(x) & & 21 & 7788,724 \\
\hline Statistics & & 22 & 7911,503 \\
\hline Correlation coefficient & 0,338 & 23 & 8034,283 \\
\hline Coefficient of determination ( $\left.\mathrm{r}^{\wedge} 2\right)$ & 0,114 & 24 & 8157,063 \\
\hline Forecast & & 25 & 8279,843 \\
\hline $\mathrm{x}=2$ & 5.455 .907 & 26 & 8402,623 \\
\hline
\end{tabular}

Sumber: Hasil pengolahan data (2019) 
Peramalan dihitung untuk periode 12 bulan ke depan sehingga dapat dihasilkan peramalan sebagai berikut:

Tabel 3. Peramalan Permintaan Kaos Periode April 2019 - Maret 2020

\begin{tabular}{|c|c|c|c|}
\hline Bulan & Permintaan & Bulan & Permintaan \\
\hline Apr & 6.806 & Okt & 7.543 \\
\hline Mei & 6.929 & Nov & 7.666 \\
\hline Jun & 7.052 & Des & 7.789 \\
\hline Jul & 7.175 & Jan & 7.912 \\
\hline Agust & 7.298 & Feb & 8.034 \\
\hline Sept & 7.420 & Mar & 8.157 \\
\hline
\end{tabular}

Sumber: Hasil pengolahan data (2019)

\section{Perhitungan Perencanaan Agregat}

Data yang didapatkan dari hasil wawancara dengan direktur, bagian produksi, dan bagian adminstrasi dan keuangan CV. X yaitu sebagai berikut: (1) Biaya tenaga kerja regular sebesar Rp. 5.500/kaos; (2) biaya lembur sebesar Rp. 12.500/jam dan maksimal lembur per hari adalah 4 jam; (3) jumlah karyawan tetap adalah 17 orang; (4) kapasitas produksi tenaga kerja per hari adalah 15 kaos; (5) biaya untuk memberhentikan karyawan sebesar Rp. 2.145.000 sesuai dengan standar rata-rata upah tenaga kerja; (6) biaya merekrut tenaga kerja yaitu sebesar Rp. 500.000; (7) harga jual kaos sebesar Rp.75.000; (8) biaya penyimpanan yang diberlakukan oleh perusahaan adalah 5\% dari harga jual yaitu Rp. 3.750; (9) jam kerja regular perusahaan maksimal yaitu 8 jam perhari dan jam lembur maksimal 4 jam; (10) perusahaan tidak menerapkan biaya kehilangan penjualan (lost sales); dan (11) perusahaan menerapkan libur kerja hanya pada hari minggu.

\section{Perencanaan Agregat Metode Level Strategy}

Tabel 4. Perencanaan Agregat Menggunakan Metode Level Strategy

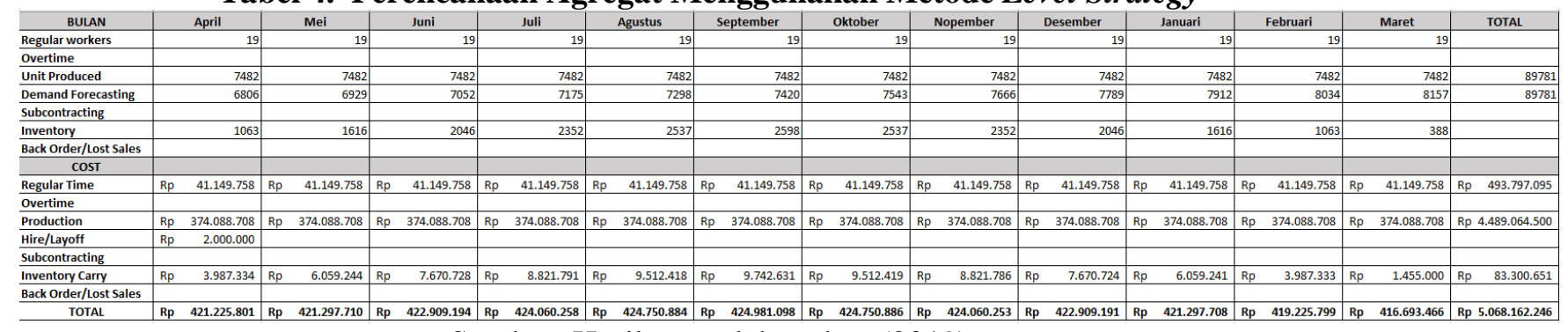

Sumber: Hasil pengolahan data (2019)

Pada alternatif metode level strategy tenaga kerja dipertahankan untuk tetap berjumlah 19 orang dengan jumlah produksi konstan yaitu 7.482 kaos dan menghasilkan total biaya produksi sebesar Rp. 5.068.162.246. 


\section{Perencanaan Agregat Metode Chase Strategy}

Tabel 5. Perencanaan Agregat Menggunakan Metode Chase Strategy

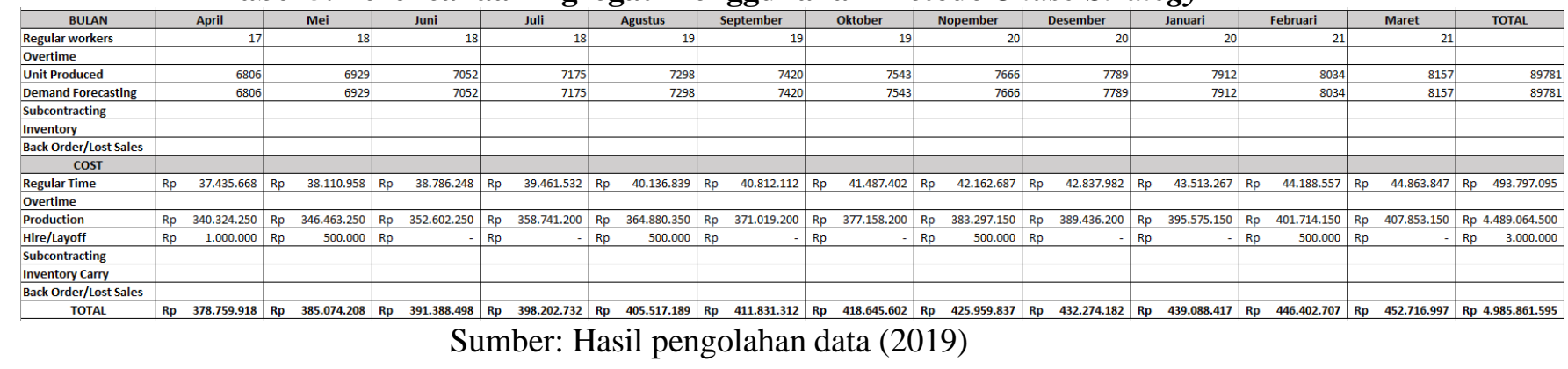

Alternatif metode chase strategy mengatur jumlah produksi sesuai dengan jumlah permintaan pelanggan sehingga terjadi fluktuasi jumlah pekerja dan menghasilkan biaya produksi sebesar Rp. 4.985.861.595.

\section{Perencanaan Agregat Metode Mixed Strategy}

Tabel 6. Perencanaan Agregat Menggunakan Metode Mixed Strategy

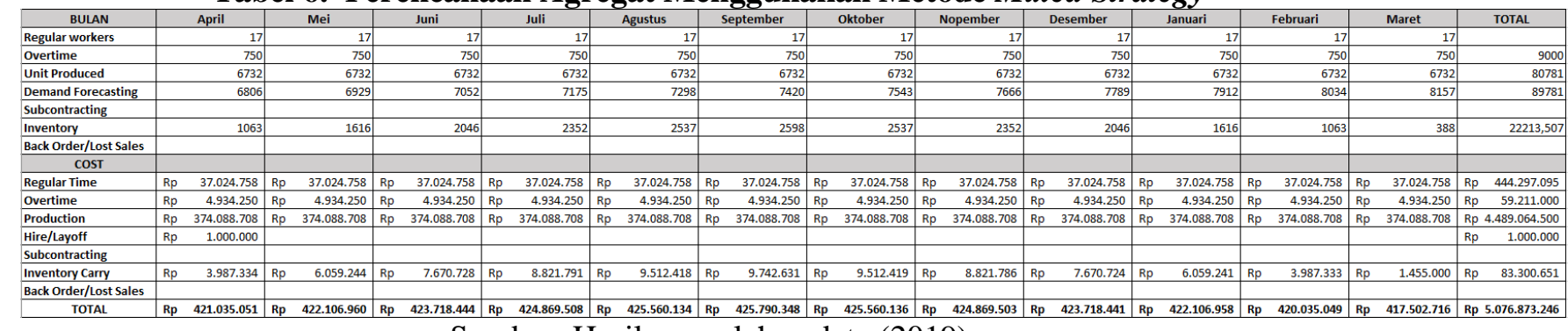

Sumber: Hasil pengolahan data (2019)

Sedangkan alternatif metode mixed strategy mengatur jumlah tenaga kerja konstan sebanyak 17 orang sekaligus menghitung kemungkinan terjadinya lembur. Strategi ini menghasilkan biaya produksi sebesar Rp. 5.076.873.246.

Tabel 7. Perbandingan Perencanaan Agregat

\begin{tabular}{|c|c|c|}
\hline No & Metode & Hasil \\
\hline $\mathbf{1}$ & Level strategy & Rp. 5.068.162.246 \\
\hline $\mathbf{2}$ & Chase strategy & Rp. 4.985.861.595 \\
\hline $\mathbf{3}$ & Mixed strategy & $\mathrm{Rp} \mathrm{5.076.873.246}$ \\
\hline
\end{tabular}

Sumber: Hasil pengolahan data (2019)

Berdasarkan hasil perhitungan perencanaan agregat dengan menggunakan tiga metode, maka metode perencanaan yang terpilih adalah chase strategy karena dengan menggunakan metode ini perusahaan mendapatkan biaya paling rendah dan efisien yaitu sebesar Rp. 4.985.861.595.

Metode chase strategy mungkin tidak selamanya menjadi metode terbaik dalam menentukan jumlah dan penjadwalan produksi yang dapat diterapkan oleh perusahaan, 
sehingga dalam setiap periode jangka menengah, perusahaan harus menghitung lalu membandingkan beberapa metode perencanaan agregat agar dapat menemukan biaya yang paling efisien.

\section{KESIMPULAN}

Berdasarkan perhitungan perencanaan agregat, metode perencanaan yang memiliki biaya paling minimum adalah metode chase aggregate plan dengan total biaya sebesar Rp. 4.985.861.595. Sehingga metode ini dapat menjadi usulan untuk perusahaan dalam melakukan perencanaan agregat agar perusahaan mampu mendapatkan keuntungan yang maksimal.

\section{DAFTAR PUSTAKA}

Akhmad. (2018). Manajemen Operasi Teori dan Aplikasi dalam Dunis Bisnis, Edisi 1. Bogor: Azkiya Publishing.

Febriyanti, Astri Refa, Nining Koesdiningsih dan Asni Mustika Rani. (2019). Meminimumkan Biaya Produksi Menggunakan Perencanaan Agregat pada CV. Moonsoon Wear Industries Kota Bandung. Vol 5, No 2, Prosiding Manajemen (Agustus, 2019) ISSN: 2460-6545.

Heizer, Jay, Barry Render dan Chuck Munson. (2017). Operation Management Sustainability and Supply Chain Management, $12^{\text {th }}$ edition. United States of America: Pearson Education.

Krajewski Lee J, Manoj K. Malhotra, Larry P.Ritzman. (2016). Operations Management Processes And Supply Chains, Eleventh Edition. England: Pearson Education Limited.

Niagahoster.co.id. (2020, 25 Mei). 15+ Produk Terlaris yang Bisa Anda Jual Secara Online. Diakses pada 3 Juli 2020, dari https://www.niagahoster.co.id/blog/produk-onlineterlaris/.

Rani, Asni Mustika. (2019). Meningkatkan Kapasitas Produksi dengan Capacity Planning (Studi pada PT XYZ). Jurnal Manajemen dan Bisnis (Performa) 16 (1), 39-49.

Reid, R. Dan dan Nada R. Sanders. (2013). Operations Management An Integrated Approach, $5^{\text {th }}$ edition. United States of America: John Wiley \& Sons, Inc.

Schroeder, Roger G. and Susan Meyer Goldstein. (2018). Operations Management In The Supply Chain: Decision And Cases , Seventh Edition. NewYork: McGraw-Hill Education. 